\title{
CHEMOTHERAPY-INDUCED NAUSEA AND VOMITING (CINV) IN A SAMPLE OF WOMEN WITH GYNECOLOGICAL CANCER: A LONGITUDINAL STUDY
}

Valentina E. Di Mattei, Phd1,2*; Letizia Carnelli, PsyD2,3; Paola Taranto, PsyD2; Martina Mazzetti, PsyD2; Martina

Bernardi, PsyD 4; Silvia Piacenti, PsyD'; Paola M.V. Rancoita, PhD'; Federica Negrini, PsyD2; Francesca Carzaniga, PsyD2; Micaela Petrone, MD2; Emanuela Rabaiotti, MD2; Massimo Candiani, MD ${ }^{1,2}$.

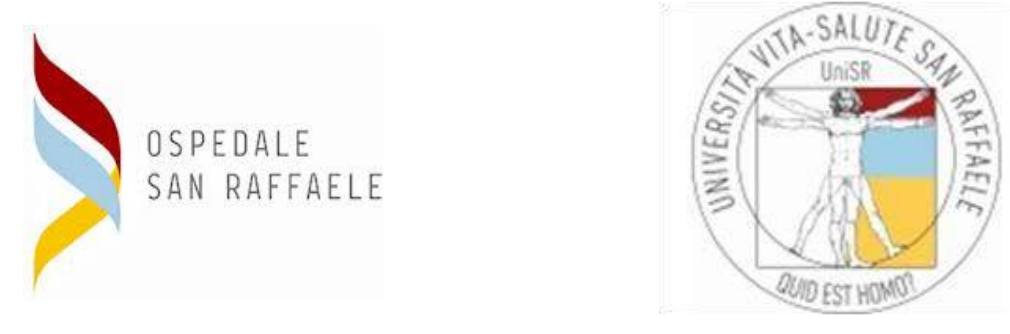

Introduction and aim

Gynecological cancer (specifically ovarian, endometrial and cervical cancer) is often subject to aggressive treatment regimens which can be associated with disabling side effects, such as nausea and vomiting, alopecia, fatigue and pain ${ }^{1,2}$.

Despite advancements in the control of emesis, chemotherapy-induced nausea and vomiting (CINV) still represents a major problem for these patients and can deeply affect their quality of life and everyday activities ${ }^{3,4}$. Moreover, evidence about CINV in gynecological cancer is still limited.

This study aimed to measure the frequency and intensity of CINV and its variation over time in a sample of women with gynecological cancer, in order to gain a better understanding of the extent to which patients experience it.

\section{Results}

The age range of the sample was 32-85 years (mean=58.19; SD=13.82). Thirty-five percent of the patients experienced acute nausea after the first infusion and $44 \%$ after the third infusion; $48 \%$ reported delayed nausea after the first infusion and $58 \%$ after the third infusion. Only a small percentage of patients (5-18\%) reported acute and delayed vomiting (Table 1). The intensity of nausea was significantly different from 0 in all four cases $(p<.001)$. A significant increase in the intensity of acute nausea $(p=.017)$ was found between the third infusion and the first (Table 2).

\begin{tabular}{|l|c|c|}
\hline \multicolumn{1}{|c|}{ Variables } & N & YES (\%) \\
\hline Acute nausea - first infusion & 121 & $42(34.7 \%)$ \\
\hline Acute nausea - third infusion & 85 & $37(43.5 \%)$ \\
\hline Delayed nausea - first infusion & 120 & $58(48.3 \%)$ \\
\hline Delayed nausea - third infusion & 85 & $49(57.6 \%)$ \\
\hline Acute vomiting - first infusion & 121 & $6(5 \%)$ \\
\hline Acute vomiting - third infusion & 83 & $12(14.5 \%)$ \\
\hline Delayed vomiting - first infusion & 120 & $22(18.3 \%)$ \\
\hline Delayed vomiting - third infusion & 85 & $14(16.5 \%)$ \\
\hline
\end{tabular}

\begin{tabular}{|l|c|c|c|}
\hline \multicolumn{1}{|c|}{ Variables } & Mean & SD & p-value \\
\hline Acute nausea intensity - first infusion & 1.421 & 2.316 & $<\mathbf{0 . 0 0 1}$ \\
\hline Acute nausea intensity - third infusion & 2.310 & 3.112 & $<\mathbf{0 . 0 0 1}$ \\
\hline Difference in acute nausea intensity & 0.753 & 2.923 & $\mathbf{0 . 0 1 7}$ \\
\hline Delayed nausea intensity - first infusion & 2.261 & 2.892 & $<0.001$ \\
\hline Delayed nausea intensity - third infusion & 2.871 & 2.999 & $<0.001$ \\
\hline Difference in delayed nausea intensity & 0.600 & 3.197 & 0.105 \\
\hline
\end{tabular}

Table 1. Frequency of acute and delayed nausea and vomiting after the first and third chemotherapy infusion.

\section{Conclusions}

The findings suggest that nausea represents an important problem that is still common among cancer patients undergoing chemotherapy; it is possible that an exhaustion of psychosocial resources and the accumulation of the effects of antineoplastic drugs contribute to the increased intensity of acute nausea over time. These should be further investigated in order to properly address these patient issues.

\section{References}

1. Chase DM, Wenzel L (2011). Health-related quality of life in ovarian cancer patients and its impact on clinical management. Expert Rev Pharmacoecon Outcomes Res, 11 (4): 421-431.

2. Casey C, Chen LM, Rabow MW (2011). Symptom management in gynecologic malignancies. Expert Rev Anticancer Ther, $11(7): 1077-89$.

3. Sommariva S, Pongiglione B, Tarricone R (2016). Impact of chemotherapy-induced nausea and vomiting on health-related quality of life and resource utilization: A systematic review. Crit Rev Oncol Hematol, 99:13-36.

4. Di Mattei VE, Carnelli L, Taranto P, et al. (2018). Quality of life and chemotherapy: predictive factors in a sample of gynaecological cancer patients. Recenti Prog Med, 109(3):193-196.

5. Molassiotis A, Coventry PA, Stricker CT, et al. (2007). Validation and psychometric assessment of a short clinical scale to measure chemotherapy-induced nausea and vomiting: the MASCC Antiemesis Tool. J Pain Symptom Manage, 34(2): 148-159. 